\section{„Ohne Freiräume keine Innovationen“}

Die Sieger des Innovationspreises der deutschen Wirtschaft stehen fest: Im Rahmen einer festlichen Gala wurde am Samstag, 15. März 2014, in Frankfurt der Innovationspreis der deutschen Wirtschaft 2014 verliehen. Auch der Klebstoffhersteller Delo erhielt diese renommierte Auszeichnung.

$\mathrm{D}$ r. Joerg Dederichs, Personaldirektor des Multitechnologie-Konzerns 3M, war eines der Jurymitglieder, die Samstagabend den Innovationspreis überreicht haben. Mit dem „Ersten Innovationspreis der Welt" werden Unternehmen und Persönlichkeiten für herausragende innovative Leistungen ausgezeichnet.

$\mathrm{Zu}$ den Preisträgern zählten BMW AG (Kategorie „Großunternehmen“), die AfB gemeinnützige $\mathrm{GmbH}$ (Kategorie „Innovative Personalkonzepte“), die Delo Industrie Klebstoffe $\mathrm{GmbH} \&$ Co KGaA (Kategorie „Mittelständische Unternehmen“) und die Abberior Instruments zu fassen: „Wir konzentrieren uns gerade in Deutschland zu stark auf Produktinnovationen. Wir müssen uns weitaus mehr mit den Voraussetzungen innovativer Leistungen befassen. Insofern begrüße ich sehr, dass mit dem Innovationspreis der deutschen Wirtschaft auch innovative Personalkonzepte gewürdigt werden." Mitarbeiterinnen und Mitarbeiter in den Unternehmen seien der Nährboden für Innovationen. Wer nicht bereit sei, entsprechende Freiräume einzuräumen und Eigeninitiative zu fördern, dürfe auch keine innovative Spitzenleistungen der Menschen erwarten. „Wenn der

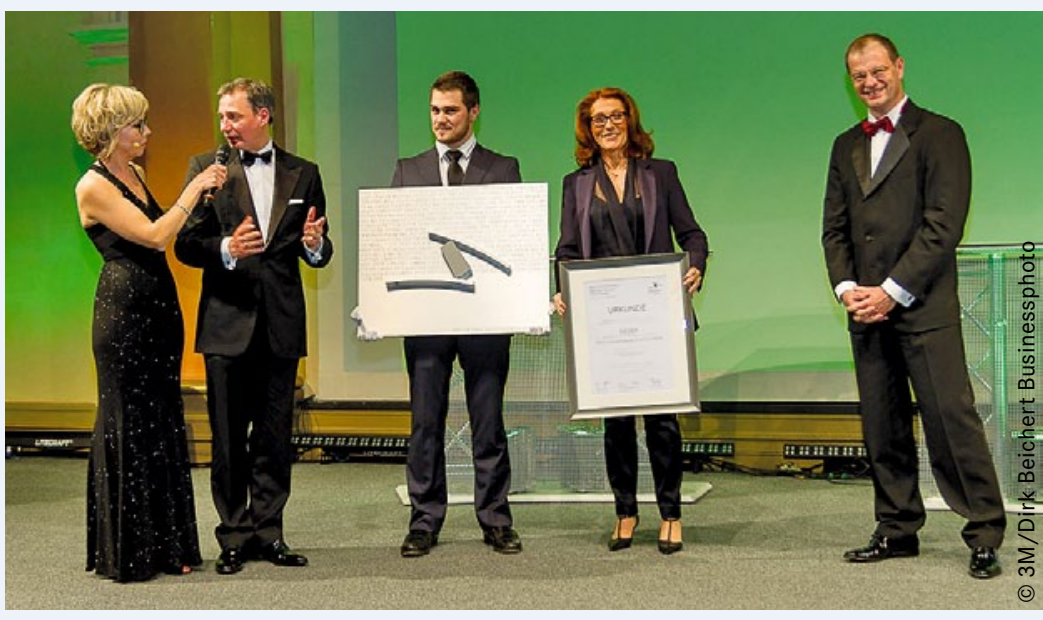

BU: n-tv-Moderatorin Corinna Wohlfeil (links) im Gespräch mit Dr. Joerg Dederichs (3M) und Stephan Kapferer (rechts), Staatssekretär beim BMWi, unter anderem mit Sabine Herold (Delo, Sieger in der Kategorie Mittelständische Unternehmen).
GmbH (Kategorie „Start-up-Unternehmen“). Der Sonderpreis „Innovativster CEO International“ ging an Jeff Bezos, Gründer und Präsident des US-amerikanischen Unternehmens Amazon.com.

Joerg Dederichs von 3M betonte die Notwendigkeit, den Fokus der Innovationsbemühungen in Deutschland breiter
Großteil der Manager in deutschen Industrieunternehmen das Arbeitsumfeld für Innovationen kritisch beurteilt, wie einer aktuellen Studie zu entnehmen ist, dann ist das ein Alarmsignal." Dederichs selbst vertritt mit 3M ein Unternehmen, das höchsten Wert auf die Kraft der Unternehmenskultur legt.

\section{Gut kontaktiert - sicher verbunden}

Mit DELO immer auf der richtigen Seite!

Ihr Klebstoffspezialist für

- SMT (Surface Mount Technology)

- Die Attach

- Chipverguss

- Schalter, Stecker, Relais

DELO live erleben!
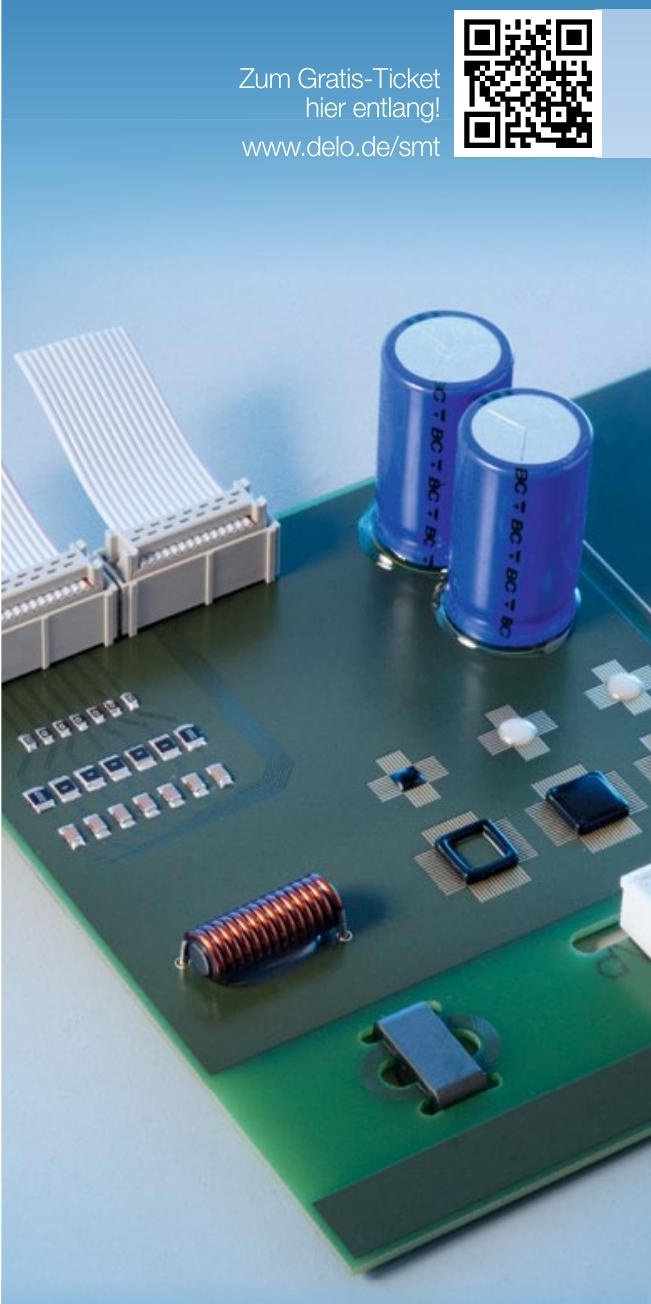

SMT in Nürnberg

6. - 8. Mai 2014 smthybridpackaging Halle 9 - Stand 429
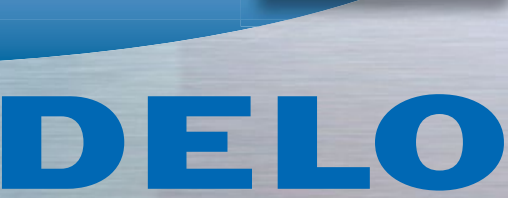

Führend durch intelligente Klebtechnik 